\title{
LA HACIENDA PÚBLICA Y LA GLOBALIZACIÓN: Reinventando el papel del Estado en la globalización de la economía.
}

\author{
Jorge Eduardo Fonseca Echeverri. \\ Fecha de Recepción: 9 de septiembre de 2011 \\ Fecha de evaluación: 9 de septiembre de 2011 \\ Fecha de aprobación: 30 de julio de 2012
}

\section{RESUMEN}

La globalización desarrolla a nivel mundial grandes ganancias por el libre intercambio de bienes y servicios; ocasionando que personas naturales y jurídicas adquieran domicilios en otros Estados y desarrollando una gran cantidad de actividades comerciales que generan grandes recursos económicos, los cuales se escapan a los sistemas tributarios de los Estados Fuente, por no poder gravar con tasas impositivas las relaciones comerciales más allá de sus fronteras.

Un Estado que no tribute, no genera recursos para cumplir con lo que Keynes, resumía como el problema político de la humanidad ${ }^{1}$. Por ello, Colombia debe intervenir la economía del mercado global a través de la hacienda pública.

\footnotetext{
* Abogado Especialista en Derecho Administrativo de la Universidad Santo Tomás de Bogotá D.C; actualmente estudiante de la III Cohorte de Derecho Público, en un convenio realizado por la Universidad Santo Tomás de Colombia y la Universidad de Constanza Alemania. fonseca_je@hotmail.com.

${ }^{1}$ : La combinación de la eficiencia económica, la justicia social y la libertad individual
} 
Palabras Clave: Globalización, Economía, Hacienda Pública, Intervención

\section{ABSTRACT}

The globalization develops large global gains from free trade in goods and services, causing natural and legal persons to acquire homes in other states and developed a lot of commercial activities that generate large economic resources, which are outside the tax system Source States, not to levy tax rates trade relations beyond their borders.

A State which is not taxed, does not generate resources to meet what Keynes summed up as the political problem of mankind. Thus, Colombia must intervene global market economy through public finances.

Keywords: Globalization, Economics, Finance and Public Intervention 


\section{INTRODUCCIÓN}

En la década de los ochenta, se implementó una crítica a la intervención del Estado en la economía, afirmando que el Estado al intervenir generaba todos los males en la economía mundial; hecho paradójico, ya que se ha evidenciado que el Estado entendido como "el conjunto de instituciones formales que procesan en su seno las demandas y presiones de diferente significado por parte de grupos organizados y que produce políticas acorde con las mismas" (Alcántara, 1995, pág. 161), es quien a través de su acción en la economía, ha tenido un papel fundamental en momentos de crisis.

Las grandes relaciones de mercado global, han generado que los sistemas tributarios de los Estados no puedan aplicar cargas impositivas a las relaciones de mercado que se presentan con sus nacionales en otros Estados; debido a que la normatividad tributaria no puede sobrepasar las fronteras; como tampoco lo podrían hacer Estados que tengan nacionales en Colombia, y los cuales obtengan incremento de su patrimonio por la realización de actividades comerciales y de mercado en nuestro país.

Actualmente el tributo sigue siendo uno de los pocos instrumentos que tiene el gobierno para mejorar su posición competitiva en la economía mundial, para atraer hacia el país recursos que permitan desarrollar planes y programas de modernización y crecimiento económico dentro del marco del Estado Social de Derecho; pero autores como Domingo Carbajo han dado a conocer la inutilidad de los sistemas tributarios nacionales para hacer frente a la globalización y plantea la necesidad de crear un tributo de base mundial, coherente con la realidad económica internacional; además de la constitución de un organismo supranacional que regule la actividad tributaria internacional que pueda: a) crear tasas sobre el flujo de capital transfronterizo que permita disminuir la volatilidad y la estabilización de los mercados financieros, que reduciría las crisis provocadas en las economías emergentes por las rápidas salidas de los capitales "golondrina"; 
b) establecer un tributo internacional para financiar la compensación de los daños causados al medio ambiente; c) crear un tributo unitario con base imponible única para las sociedades transnacionales, la cual se repartiría posteriormente entre las diferentes naciones a partir de un criterio más o menos objetivo; d) La creación de impuestos que graven operaciones propias de países desarrollados, caso de los viajes de avión y el comercio de armas; para financiar proyectos de desarrollo y e) la creación de impuestos a las Tecnologías de la Información y de la Comunicación (TIC) por el flujo de información que se recibe a cada segundo por medio de bits y que en su mayoría hacen relación o tienen relación con actividades de prestación de bienes y servicios.

Otro aspecto importante a resaltar, es que a través de la intervención del Estado en la Economía por medio de la Hacienda Pública, se podría lograr un mayor control de actividades ilícitas que se mueven a través de las actividades lícitas de mercado; como es el lavado de activos provenientes de organizaciones como el narcotráfico, que han inyectado a países grandes cantidades de moneda extranjera, lo que ocasiona fluctuaciones en la tasa representativa del mercado.

Colombia, no ha sido ajena a toda esta problemática y a través del Gobierno Nacional se han dado pequeños pasos, celebrando convenios fundamentados en el modelo de la Organización para la Cooperación y el Desarrollo Económico (OCDE), con el Reino de España y Chile, que buscan evitar la doble tributación y prevenir la evasión y elusión fiscal y distribuir la potestad tributaria (Dirección de Impuestos y Aduanas Nacionales, 2010); pero esto solo es el comienzo y el tema debe desarrollar gran interés y trabajo mancomunado entre abogados y economistas que busquen establecer normas y procedimientos en la relaciones del mercado global y la imposición de gravámenes que permitan al Estado captar recursos; y por qué no, presentar una propuesta que permita la creación de un organismo internacional como lo ha indicado Domingo Carvajo. (Globalización y Hacienda Pública).

\section{LA NECESIDAD DE INTERVENCIÓN.}


La economía globalizada de mercado, es inherentemente inestable, genera crisis y ciclos económicos, no se auto-regula; ni si quiera los organismos multinacionales globales como el Fondo Monetario Internacional (FMI), el Banco Mundial (BM) o la Organización Mundial del Comercio (OMC), pueden resolver e imponer normas y comportamientos a la economía global, y a los conflictos o problemas que ellas presentan, no le pueden dar estabilidad; como tampoco lo pueden hacer organismos gubernamentales conformados a través de tratados suscritos por varios países (por ejemplo la Unión Europea).

En 1997, en plena globalización, el Banco Mundial aseveró, en su informe sobre el desarrollo mundial, El Estado en un mundo en transformación, que

$<<\ldots$ las enseñanzas de los grandes éxitos conseguidos... desde la industrialización de algunos países en el siglo XIX hasta el crecimiento "milagroso" alcanzado en la postguerra por Asia Oriental..., lejos de respaldar la teoría del Estado Minimalista, demuestran que el desarrollo exige la existencia de un estado eficaz... La historia ha demostrado una y otra vez que el buen gobierno es una necesidad vital, no un lujo. Sin un Estado eficaz, es imposible alcanzar un desarrollo sostenible, ni el plano económico ni en el social>> (Banco Mundial, 1997)

La Comisión Económica para América Latina y el Caribe CEPAL (Globalization and Development, 2002) sostuvo que

$<<$ Uno de los más serios errores hechos en el último cuarto del siglo XX fue el de promover una "sola solución"... que se apoyaba en el principio de la liberalización plena del mercado. La tendencia a equiparar una integración exitosa al mundo globalizado con la liberación económica no considera el hecho de que muchas estrategias exitosas no se ha apoyado en una apertura total al mercado sino, más 
bien, en varios caminos para armar, articular "un circulo virtuoso" entre el Estado y el mercado>>

Así mismo, en el 2004 el Programa de las Naciones Unidas para el Desarrollo PNUD (La Democracia en America Latina) propone la necesidad de:

$<<$ un Estado capaz de conducir el rumbo general de la sociedad, procesar los conflictos conforme a reglas democráticas, garantizar eficazmente el funcionamiento del sistema legal, preservar la seguridad jurídica, regular los mercados, establecer equilibrios macroeconómicos, fortalecer sistemas de protección social basados en los principios de universalidad y asumir la preeminencia de la democracia como principio de organización social.

GARCIA DE LA CRUZ (Madrid. 2007) expuso que es preciso volver a plantear la oportunidad y la posibilidad de intervención pública.

La función económica del Estado no será solamente la corrección de las fallas del mercado, sino que puede suplir al mismo en cuestiones tales como la coordinación de decisiones y la orientación de las mismas hacia objetivos que satisfagan las necesidades sociales por encima de las privadas.

En la actualidad ha transcurrido más de veinte años, en los cuales se ha hecho evidente la preocupación de hacer ver la necesidad de que el Estado intervenga en la economía; las razones por las que el Estado interviene en la economía no son estrictamente económicas, se debe también, a razones de índole político e histórico; Hilario Barcelata Chávez ( Gasto Público y Sector Paraestatal en México, 2010) manifiesta tres categorías en el cual el Estado interviene en la economía bajo diversas modalidades, a distintos niveles de profundidad y con distintos grados de influencia; estas modalidades son de tres tipos: 
a) Garantía del orden, administración de justicia, proporción del marco jurídico. (Ejemplo: garantizar los derechos de propiedad, el cumplimiento de los contratos, la libertad, etcétera.)

b) Regulación mediante la política económica (fiscal, monetaria, comercial y laboral)

c) Conducción económica mediante la producción y provisión de bienes del sector paraestatal

El Estado es el responsable en la conducción del proceso de desarrollo económico y social; y al reconocerse que la economía requiere para funcionar de una mayor presencia y acción del Estado, aparece frente a la mano invisible del mercado la mano visible del Estado, para alcanzar principios como justicia, equidad, eficiencia y progresividad; para lo cual se necesita de un sistema que lo dote de recursos para el cumplimiento de sus funciones y es ahí donde la Hacienda Pública y el sistema tributario desempaña un papel fundamental en la consecución y defensa de estos intereses.

\section{EL ESTADO Y LA HACIENDA PÚBLICA.}

El Estado es un sujeto económico, pues requiere de recursos económicos para sus fines y para tal fin un estudio de cómo el Estado obtiene estos recursos, la hace la Hacienda Pública.

Dada la apertura económica, la globalización y la creación de grandes grupos económicos; - en la actualidad - el Derecho Tributario del Estado y de las relaciones de este con los demás Estados, ha ocupado un papel importante, en las relaciones internacionales. 
Dentro de las instituciones públicas con las que cuenta un Estado está la Hacienda Pública; Domingo Carbajo Vasco (Globalización y Hacienda Pública, 2007), afirma que una de las actividades económicas donde se manifiesta de manera más clara la incidencia de la globalización es en el sistema tributario.

Mientras que el tributo responde a una concepción nacional, vinculado al Estado moderno; la globalización provoca que alguno de los fundamentos de la soberanía tributaria del Estado entre en crisis; la globalización empuja la alteración de las participaciones de los países en la actividad económica mundial, al punto de perfilar nuevos centros de producción, comercio y finanzas, los cuales no están sujetos a cargas impositivas.

Ulrich Beck, (¿Qué es la globalización?, 2002), ha expuesto la ostensible inequidad a que conduce el mundo globalizado, al facilitar que grandes empresas multinacionales reduzcan efectivamente los impuestos a su cargo mediante la apelación a paraísos fiscales o recintos de menor imposición; en tanto, que las empresas medianas y pequeñas, incapacitadas como están para acudir a complejas estrategias para la localización de sus utilidades en paraísos, se ven compelidas a asumir no solo los tributos que les corresponde sufragar, sino los que pagan al Estado multinacional; lo que se ha denominado como contribuyentes reales y contribuyentes virtuales.

¿Cómo se manifiesta la incidencia de la globalización en el sistema tributario? En las relaciones comerciales de los nacionales que se adelantan en dos o más Estados, lo cual genera la necesidad de regular los tributos.

La forma más sencilla de regular los tributos de esas relaciones comerciales, de un nacional con dos o más Estados, es a través de tratados bilaterales o multilaterales, o por medio de soluciones supranacionales; es decir, a través de organismos internacionales con facultades de expedición de normas aplicables a todos los países signatarios del tratado. 
Carbajo, propone la creación de una "Autoridad Tributaria Internacional" ante la inutilidad de los sistemas tributarios nacionales para hacer frente a la globalización y a la imposición de un tributo mundial, coherente con la realidad económica en la cual nos movemos; o por el contrario, si se conserva una fragmentación entre Administraciones Tributarias, la utilización de mecanismos de "second best" para hacer frente a la globalización, en especial, utilizando los acuerdos de coordinación y asistencia mutua entre las administraciones tributarias nacionales y creando organismos de cooperación interadministrativa que actúen sobre la deslocalización de contribuyentes y bases tributarias, aplicando tributos conjuntos.

El tributo es uno de los pocos instrumentos que se encuentran en manos de los Estados para mejorar su posición competitiva en la esfera económica mundial, lo que agudiza la búsqueda de "regímenes fiscales preferenciales" o de "nichos" tributarios para atraer hacia su territorio actividades de mercado, generando políticas de "competencia tributaria"; por lo que es probable que los Estados no transfieran esta institución a organismos internacionales y más cuando el tributo es la base para atraer mercados, generando ingresos que se destinan al desarrollo de las funciones del Estado.

La contraposición entre sistemas fiscales nacionales lentos y las realidades socioeconómicas globalizadas cambiantes, requiere el desarrollo de sistemas tributarios que aprovechen los aspectos favorables de cada nación, para atraer a sus territorios actividades económicas de no residentes que produzcan una carga impositiva, para obtener un determinado nivel de recaudación interna que asegure la cohesión del Estado y la provisión de bienes públicos.

La Hacienda pública en los Estados no puede estar al margen de la globalización; antiguos conceptos e ideologías fiscales desarrolladas hace muchos años deben transformarse y adaptarse a las relaciones de economía de mercado global; además de la realidad económica local y regional; para enfrentar el paradigma de 
una hacienda nacional que no puede tener injerencia más allá de sus fronteras y de las actuaciones de particulares que con actividades licitas e ilícitas de mercado, eluden el control del Estado.

Martí Borbolla manifestaba que el Estado moderno necesita una reinvención, entendiendo como reinventar - en el sentido más puro habermaseano - desarmar un concepto y reagruparlo de una forma distinta para así alcanzar mejor el objetivo que éste se había propuesto originalmente -, que le inyecte una nueva vida y justificación. (La reinvención de la soberanía en la globalización: perspectivas y alcances de la soberanía del estado democrático constitucional en un mundo interdependiente, 2007)

Los Estados en otrora, controlaban el territorio y de esta forma controlaban la riqueza, el control de sus fronteras les permitía recaudar impuestos, existía una simetría entre lo económico y lo político, entre el Estado y el mercado; la globalización rompe esta simetría, acabando con la economía de territorio; redefiniendo el concepto de soberanía, al no poder disponer los Estados de todos los instrumentos de política económica.

La mundialización ha matado el mercado nacional, uno de los fundamentos del poder Estado Nacional. El mercado no tiene referencias de espacio y tiempo, de economía real; tal es la lógica de los regímenes globalitarios que se han creado imperios económicos que elaboran sus propias leyes, que deslocalizan sus puntos de producción y desplazan sus capitales a gran velocidad; lo que genera la evasión de cargas impositivas y el ingreso soterrado de actividades ilícitas.

La apertura actual de los mercados, exige la reinvención del concepto de soberanía estatal y del papel del Estado en la regulación de la economía, que traiga como consecuencia la localización de actividades económicas globales bajo los imperativos criterios de justicia, equidad, eficiencia y progresividad. 
Luis Felipe Martí Borbolla plantea que

Existe la necesidad de instalar en la vida económica la democracia, la necesidad de volver las decisiones económicas al ámbito de la decisión pública, no por un perverso afán regulador e intervencionista de poder político sobre el sistema económico, sino para garantizar las condiciones que hagan efectivo el autogobierno y la autonomía democrática de los habitantes de este planeta. Esto es, para garantizar el fin al que la economía siempre deberá servir como instrumento.

La generación de una autoridad tributaria internacional, requiere de autoridades tributarias nacionales y locales que mediante el flujo de información, puedan regular la carga impositiva de los nuevos centros de producción, comercio y finanzas transnacionales; para evitar que mercados lícitos e ilícitos, mediante el ejercicio de las operaciones de mercado, eludan la responsabilidad tributaria imperante en cada Estado.

En Colombia, se ha adoptado una estructura tributaria acorde con el contexto económico, político y social del país; diferente a las tendencias que se han adoptado por ejemplo en el Reino Unido, donde hay dos organizaciones: una encargada de controlar los impuestos indirectos y ejercer el control aduanero $(H$. M. Customs and Excise) y otra que se encarga de los impuestos directos y las contribuciones a la seguridad social (Inland Revenue); o como en Francia, Canadá e Italia, que se aplica el modelo funcional, es decir, atendiendo a las diferentes funciones de la administración.

Es así como en Colombia, el 1ํ de Junio del año 1993 se fusionó la Dirección de Impuestos Nacionales (DIN) con la Dirección de Aduanas Nacionales (DAN), en la Dirección de Impuestos y Aduanas Nacionales (DIAN), constituyéndose como una Unidad Administrativa Especial, del orden nacional, de carácter eminentemente técnico y especializado, con personería jurídica, autonomía administrativa y 
presupuestal y con patrimonio propio, adscrita al Ministerio de Hacienda y Crédito Público; que tiente entre otras, la finalidad de garantizar la seguridad fiscal del Estado colombiano y la protección del orden público económico nacional, mediante la administración y control al debido cumplimiento de las obligaciones tributarias, aduaneras y cambiarias, y facilitando las operaciones de comercio exterior en condiciones de equidad, transparencia y legalidad.

En el transcurso de estos 17 años de creación de la DIAN, se han efectuado grandes reformas tributarias - ocho (8) - destinadas a congregar nuevos recursos para el Estado; lo que ha generado un incremento en forma sostenida de la base tributaria en Colombia, en proporción del Producto Interno Bruto (PIB) desde 1990, lo que revela un esfuerzo fiscal creciente en este sentido.

Caso contrario, sucedía con el Gravamen Arancelario, que tuvo una fuerte caída a comienzos de la década de los 90, década en la que se presentó una fuerte apertura de la economía Colombiana. Entre 1993 y 2001, la recaudación se mantuvo sobre el 1\% del PIB durante la mayor parte del tiempo, y a partir de 2001 ha tendido a caer en forma sistemática.

Otro hecho que se presentó con la globalización y la hacienda pública en Colombia, fue el fenómeno de la doble tributación y los conflictos que enfrentaban las administraciones tributarias de los países, en los cuales se desarrollaban al mismo tiempo actividades comerciales que generaban renta, trayendo como consecuencia la doble imposición de tributos a los nacionales en ambas naciones.

\section{LA DOBLE IMPOSICIÓN.}

El Gobierno Nacional con el fin de evitar la doble tributación y prevenir la evasión y elusión fiscal, celebró acuerdos solemnes entre Estados soberanos contratantes que tienen como finalidad distribuir la potestad tributaria entre ellos para evitar que sus residentes estén sometidos a doble imposición. 
Ante este hecho, el 27 Diciembre de 2006, se expidió en Colombia la Ley № 1111, que modificó el Estatuto Tributario; permitiéndole a los contribuyentes nacionales (Colombianos) que recibían rentas de fuentes extranjeras, sujetas al impuesto sobre la renta en el país de origen, a descontar del monto del impuesto colombiano de renta, el pagado en el extranjero sobre esas mismas rentas, siempre que el descuento no excediera del monto del impuesto que deba pagar el contribuyente en Colombia por renta. En ningún caso el descuento a que se refiere el inciso, podría exceder el monto del impuesto de renta generado en Colombia por dividendos.

Esta modificación al Estatuto Tributario Colombiano, se originó por la firma del "Convenio entre el Reino de España y la República de Colombia para evitar la doble imposición y prevenir la evasión fiscal en materia de impuestos sobre la renta y sobre el patrimonio", el 31 de Marzo de 2005; convenio que fue ratificado mediante la Ley 1082 de 2006 y declarado exequible por la Honorable Corte Constitucional, mediante sentencia C - 383 de 2008 al considerar que ... los objetivos y el contenido del convenio sometido a control constitucional, que como quedó dicho, busca facilitar a los ciudadanos y empresas de los países signatarios los instrumentos que les permitan no ser sujetos de doble imposición tributaria por parte de ambos Estados, se avienen sin dificultades al contenido de los preceptos superiores aplicables.

De esta forma se pone freno a la evasión por medio del intercambio de información entre las actividades tributarias de ambos países, el control de lavado de activos proveniente de actividades ilícitas de organizaciones delincuenciales internacionales y transnacionales, y la disminución de cargas fiscales para los inversionistas.

Los tratados actualmente vigentes para evitar la doble tributación y la evasión fiscal son: La Decisión Nº578 del 2004. Acuerdo de la Comunidad Andina de 
Naciones CAN - norma supranacional -, disposiciones que surten efecto desde el primero de Enero de 2005; el Convenio celebrado entre el Reino de España y la República de Colombia (Ley 1082 del 2006), disposición que se aplica desde el 23 de Octubre de 2008.; y El Convenio celebrado entre la República de Chile y la República de Colombia (Ley 1261 de 2007), que rige para el impuesto sobre la renta a partir del primero de Enero de 2010.

\section{CONCLUISONES}

La evolución de la economía mundial no se ha detenido, no hay fin de la historia, sino renacimiento de oportunidades como el papel que entra a jugar el Estado en la intervención de la economía y la responsabilidad que tiene en la conducción del proceso de desarrollo económico y social; para lo cual es necesario revisar el concepto de Estado Bienestar.

Ante la crisis financiera, la hacienda pública y el Estado han asumido un nuevo rol. La reinvención de la hacienda pública es imperativa y su poder de ejercicio debe traspasar las fronteras; para lo cual debe asumir nuevas funciones que estén a la par del mundo volátil y cambiante de los mercados, para acceder a ellos e imponer cargas tributarias a las relaciones que genere el normal ejercicio de los mercados.

Una globalización absoluta, es como una libertad absoluta; una libertad absoluta sin autolimitación, se destruye; por ende, la globalización no debe ser absoluta, debe auto limitarse; en la globalización de la economía y de los mercados la autolimitación sería la imposición de tributos a través de una hacienda pública estatal, lo que llevaría a la reinvención del papel de Estado en la globalización de la economía a través de la hacienda pública.

Se requiere aumentar la celebración de convenios para evitar la doble tributación entre Colombia y los estados partes. Establecer la importancia que tiene el papel del Estado en la economía de un mundo globalizado, al imponer cargas tributarias 
a los nacionales y a los residentes en el territorio nacional; por lo que se requiere desarmar el concepto de Hacienda Pública y reagruparlo de una forma distinta para alcanzar mejor el objetivo que éste se había propuesto originalmente, inyectándole una nueva vida y justificación.

\section{BIBLIOGRAFÍA.}

Alcántara, M. (1995). Gobernabilidad, crisis y cambio. Méjico: Fondo de Cultura Económica.

Banco Mundial. (1997). Informe sobre el desarrollo mundial 1997.

Barcelata Chávez, H. (2010). Gasto Público y Sector Paraestatal en México. España: Universidad de Málaga.

Beck, U. (2002). ¿Qué es la globalización? Taurus.

Carbajo Vasco, D. (2007). Globalización y Hacienda Pública. En S. M. Ruesga Benito, \& Á. S. Diez (Ed.), El Estado ante la globlización (pág. 350). Madrid, España: Marcia Pons.

Comisión Económica para América Latina y el Caribe . (2002). Globalization and Development. New York.

Dirección de Impuestos y Aduanas Nacionales. (2010). Convenios para evitar la doble imposición y evitar la evasión fiscal en relación a los impuestos a la renta y al patrimonio. Bogotá.

Martí Borbolla, L. F. (2007). La reinvención de la soberanía en la globalización: perspectivas y alcances de la soberanía del estado democrático constitucional en un mundo interdependiente. Méjico: Porrua. 
Programa de las Naciones Unidas para el Desarrollo. (2004). La Democracia en America Latina. Buenos Aires: Taurus. 